\title{
Las Cofradías de Pescadores en Euskadi como entidades de la economía social ${ }^{\&}$
}

\author{
The Fishermen's Associations in the Basque Country as entities \\ of the Social Economy
}

\author{
Francisco Javier Arrieta Idiakez*1, Gonzalo Martínez EtXeberria², \\ Josune López RoDRÍGuEz ${ }^{3}$ \\ ${ }^{1}$ Profesor titular de Derecho del Trabajo y de la Seguridad Social. Universidad de Deusto \\ ${ }^{2}$ Profesor doctor de Derecho Constitucional. Universidad de Deusto \\ ${ }^{3}$ Profesora doctora de Derecho Social. Universidad de Deusto
}

\begin{abstract}
Resumen: A través de este estudio se pretende justificar que las Cofradías de Pescadores de Euskadi encajan en el concepto de entidad de la Economía Social que establece la Ley 5/2011, de 29 de marzo, de Economía Social. Ciertamente, se considera que no es suficiente con que dicha ley mencione a las Cofradías de Pescadores como entidad de la Economía Social, sino que es necesario que, en la práctica, se cumplan determinados principios, fácilmente identificables en la propia ley. Para ello, en primer lugar, se llevará a cabo una caracterización de las Cofradías de Pescadores de Euskadi, principalmente, para demostrar que, pese a su naturaleza jurídica de Corporación de Derecho Público, cumplen con el principio de independencia respecto a los poderes públicos. A continuación, se analiza si, en la práctica, las Cofradías de Pescadores cumplen con el resto de principios orientativos de la Economía Social, y si también desarrollan actividad económica y satisfacen bien el interés colectivo de sus integrantes, bien el interés general económico y social, o ambos. Debe destacarse que para llevar a cabo este estudio se han analizado pormenorizadamente todos los Estatutos de las Cofradías de Pescadores de Euskadi.
\end{abstract}

Palabras clave: Cofradías de Pescadores; Euskadi; Economía Social; cohesión social; sostenibilidad medioambiental.

\begin{abstract}
By means of this study, we aim to justify that the Basque Fishermen's Associations fit into the concept of a Social Economy entity established by the Law 5/2011, from March 29, on Social Economy. Certainly, we consider that it is not enough that the aforementioned Law mentions the Fishermen's Associations as an entity of the Social Economy, but it is necessary that, in practice, certain principles, easily identifiable in the Law, are complied. To that end, first, we will carry out a characterization of the Basque Fishermen's Associations, in particular, in order to prove that, despite their legal nature of Public Law Corporation, they comply with the principle of independence from public powers. Then, we will analyse if, in practice, the Fishermen's Associations comply with the rest of the guiding principles of the Social Economy, and if they also develop economic activity and satisfy the collective interest of their members, either the general economic and social interest, or both. It should be noted that in order to carry out this study, we have analysed in detail all the Statutes of the Basque Fishermen's Associations.
\end{abstract}

Keywords: Fishermen's Associations; Basque Country; Social Economy; social cohesion; environmental sustainability.

Claves Econlit: K39, L53, M14

\& Este artículo es parte del resultado de la investigación desarrollada dentro del proyecto «Construcción del relato de la Economía Social (Neurtzen II)», financiado por la Dirección de Economía Social del Departamento de Trabajo y Justicia del Gobierno Vasco durante 2019.

* Correspondencia a/Corresponding author: Francisco Javier Arrieta Idiakez. Universidad de Deusto. Departamento de Derecho Privado) - javier.arrieta@deusto.es - https://orcid.org/000-003-4696-6356

Cómo citar/How to cite: Arrieta Idiakez, Francisco Javier; Martínez Etxeberria, Gonzalo; López Rodríguez, Josune (2021). «Las Cofradías de Pescadores en Euskadi como entidades de la economía social», GIZAEKOA - Revista Vasca de Economía Social, 18, 109-133. (https://doi.org/10.1387/gizaekoa.22903).

Recibido: 27/05/2021; aceptado: 10/06/2021.

ISSN 1698-7446 - eISSN 2444-3107 / (c) 2021 UPV/EHU

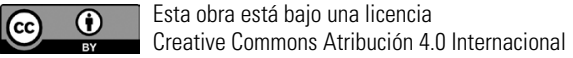




\section{Caracterización de las Cofradías de Pescadores}

Las Cofradías de Pescadores se definen tanto legalmente como por la doctrina científica.

Comenzando por las definiciones legales, conforme a la Ley 3/2001, de 26 de marzo, de Pesca Marítima del Estado:

Las Cofradias de Pescadores son corporaciones de Derecho público, sin ánimo de lucro, representativas de intereses económicos, que actúan como órganos de consulta y colaboración de las administraciones competentes en materia de pesca marítima y de ordenación del sector pesquero. (Artículo 45.1)

En el ámbito de la Comunidad Autónoma de Euskadi, de acuerdo con la Ley 16/1998, de 25 de junio, de Cofradías de Pescadores:

Las Cofradias de Pescadores son corporaciones de Derecho público dotadas de personalidad jurídica y capacidad de obrar para el cumplimiento de sus fines, que se instituyen legalmente como cauce participativo y colaborador del sector pesquero con las Administraciones públicas en defensa del interés general de la pesca, el marisqueo y la acuicultura, y de la organización y comercialización de sus productos. (Artículo 1).

Por su parte, CEPES ofrece una definición mucho más acorde a los principios de la Economía Social, al considerar que:

Las Cofradias de Pescadores son corporaciones de Derecho público sectoriales, sin ánimo de lucro, representativas de intereses económicos de armadores de buques de pesca y de trabajadores del sector extractivo, que actúan como órganos de consulta y colaboración de las administraciones competentes en materia de pesca maritima y de ordenación del sector pesquero, cuya gestión se desarrolla con el fin de satisfacer las necesidades e intereses de sus socios, con el compromiso de contribuir al desarrollo local, la cohesión social y la sostenibilidad. ${ }^{1}$

Al fin y a la postre, estas definiciones son fruto de un importante legado histórico. Así, el origen de las Cofradías de Pescadores de Euskadi debe ubicarse «dentro de la corriente corporativista que se extiende durante la Baja Edad Media por el escenario continental» (ERKOREKA GervaSIo, 1991, p. 32). Más concretamente, podemos referirnos a las Cofradías

1 https://www.cepes.es/social/entidades_cofradias_pescadores (última consulta: 25 de mayo de 2021). 
como una institución perfectamente organizada en toda la costa cantábrica a partir de la segunda mitad del siglo XIV (Arrieta Idiakez, 2007, p. 34).

En una primera fase, no fueron otra cosa que «la reunión de todos los profesionales pesqueros de una misma localidad que se colocaban bajo la advocación de un santo, al que designaban su patrón, para la práctica de sus deberes religiosos» (Lledó Martín, 1943, p. 130). Pero, posteriormente, en una segunda fase, surge la Cofradía como agrupación profesional o gremial (Rumeu de Armas, 1944, pp. 30, 55 y 56). Es entonces cuando puede apreciarse ya la verdadera naturaleza jurídica de esta institución. En efecto, las Cofradías comenzaron a regular a través de sus correspondientes ordenanzas la actividad marítimo-pesquera en todos sus aspectos, incluyendo los fines religioso-benéficos de la primera fase. Con razón se ha llegado a decir que «en dichos organismos se hermanaba perfectamente lo espiritual con lo material, lo social y lo económico (Lledó MarTín, 1943, p. 130). De este modo, las Ordenanzas se encargaban de regular diferentes facetas de la vida de los mareantes. Tendrán su propia jurisdicción para conocer de las disputas surgidas en torno a cualquier aspecto de la vida profesional; se ocuparán de la ordenación de la profesión mareante, poniendo especial énfasis en la garantía de la seguridad profesional; regularán la venta del pescado capturado por los cofrades; llevarán a cabo diversas actividades religiosas; organizarán fiestas; se encargarán del aprovisionamiento de artes y de cebo; llevarán a cabo la construcción y mantenimiento de muelles portuarios; ordenarán las levas de marinería en el ámbito intragremial; regularán las relaciones laborales y de asistencia social entre los cofrades; y, en general, defenderán los intereses económicos y políticos convenientes para los cofrades (Arrita IdiAKez, 2007, p. 37).

La importancia de esta organización queda de manifiesto si observamos que perdura incluso después del advenimiento de la revolución industrial, cuando decaen los gremios. Así, durante los siglos XIX y Xx, «bajo distintas apariencias institucionales, las Cofradías supusieron un sistema para asegurar la explotación económica de una manera colectiva de un área costera» (Franquesa, 2005, p. 4).

Su carácter o naturaleza de corporación de Derecho Público trae causa precisamente de esa especial capacidad que han tenido para ir adaptándose institucionalmente según los avatares de cada tiempo. Concretamente, hay que remontarse al franquismo para identificar por vez primera a las Cofradías de Pescadores como corporación de Derecho Público. Durante la transición, con el Real Decreto-Ley 31/1977, se sientan las bases para continuar, aunque de manera renovada, otorgándoles la misma naturaleza. Y con fundamento en dicha disposición, las distintas normas estatales y autonómicas que se han encargado de regular las Cofradías de Pescadores han mantenido dicha calificación. Pero ¿qué supone esa consideración? 
¿Cuál es su relevancia jurídica? $\mathrm{Al}$ respecto, pueden realizarse las siguientes apreciaciones (Rebollo Puig, Falcón y Tella y López Benítez, 1996, pp. 29-34 y 37-38):

a) El hecho de que las Cofradías de Pescadores sean corporaciones indica que su elemento esencial son las personas que las componen y que es la voluntad de las mismas personas la que ha de conformar la de la corporación. De ahí que se estructuren internamente de acuerdo a técnicas que garanticen la representatividad del grupo en los órganos superiores.

b) Se trata de corporaciones sectoriales porque el conjunto de personas que las forman pertenecen a un grupo humano caracterizado por su relación profesional con la pesca.

c) Son corporaciones de Derecho público porque han sido creadas por el poder público para unos concretos fines y son esos los que tienen que atender. Precisamente, esta característica conlleva una especial conexión con la Administración pública, si bien hay que matizar que la incidencia de los poderes públicos es muy inferior en las Cofradías de Pescadores que en otras corporaciones similares y que su realización de actividades administrativas es también menor. Ciertamente, lo que parece justificar su mantenimiento como Corporaciones de Derecho público es que siguen siendo necesarias para la consecución de los fines públicos implicados en la política pesquera. Es decir, se toma en consideración una actividad privada que interesa a un determinado grupo pero que tiene una relevancia social general. Precisamente para garantizar el buen desarrollo de dicha actividad se otorga la naturaleza de Corporación de Derecho Público a las Cofradías de Pescadores. Y ello conlleva la encomienda o imposición de actividades que lógicamente benefician al sector, pero que se consideran necesarias o relevantes para el interés general. Por su parte, la Administración se limita a desempeñar una labor de vigilancia.

En último término, se ha señalado que las Corporaciones de Derecho Público de carácter sectorial son «organizaciones de base y fines privados, pero con una dimensión pública por su conexión con el interés público» (Paniagua Zurera, 2011, p. 215). En concreto, esa dimensión pública que deriva de su conexión con el interés público se manifiesta en la idea ya apuntada de que, conforme al artículo 1 de la Ley 16/1998, de 25 de junio, de Cofradías de Pescadores, de la Comunidad Autónoma de Euskadi, "se instituyen legalmente como cauce participativo y colaborador del sector pesquero con las Administraciones públicas en defensa del interés general de la pesca, el marisqueo y la acuicultura, y de la organización y comercia- 
lización de sus productos». Además, puede considerarse que dicha defensa se relaciona con el compromiso para con el desarrollo local. En esa línea, los propios Estatutos de las Cofradías de Pescadores establecen que estas actúan como «órgano de consulta de la Administración en la preparación, aplicación y elaboración de normas que afecten a temas de interés general pesquero", así como "órgano de colaboración con la Administración sobre acciones o reformas para el desarrollo y mejora de la industria extractiva de la pesca, el marisqueo y la acuicultura, y su comercialización, contemplados en función del interés común del sector» (vid. Estatutos de las Cofradías de Pescadores de Armintza, Bermeo, Lekeitio, Zierbena y Santurtzi). Y entre los fines de las Cofradías de Pescadores, se fijan, entre otros, los relativos a «actuar como entidad de consulta y colaboración con las Administraciones públicas en el ámbito general de la actividad y de la comercialización de los productos de la pesca, el marisqueo y la acuicultura», "emitir y elevar informes y propuestas a la Administración sobre las disposiciones legales, las medidas estructurales y socioeconómicas, los planes de actividad y la regulación y ordenación del mercado de los productos pesqueros», «ejercer en su ámbito territorial las funciones que les sean delegadas por las Administraciones públicas en materias que afecten al sector pesquero profesional», «adoptar las medidas necesarias para que se realice el desembarco y venta de los productos pesqueros de acuerdo con las normas legales establecidas", "confeccionar y presentar las estadísticas de capturas y ventas de acuerdo con las instrucciones del Departamento competente en materia de pesca; «vigilar por la seguridad de barcos y tripulantes» (vid. Estatutos de las Cofradías de Pescadores de Armintza, Bermeo, Lekeitio, Orio, Zierbena y Santurtzi); "prestar servicio de administración y asesoramiento en toda la operativa relacionada con la Seguridad Social y prestaciones complementarias» (vid. Estatutos de las Cofradías de Pescadores de Donostia, Getaria, Hondarribia y Pasajes).

Es más, con fundamento en todo ello, se afirma por la doctrina científica que «la tutela administrativa no afecta a la actividad económica y empresarial o no, al menos, en el sentido de impedir la adopción de acuerdos cofradiales autónomos, dirigidos al mercado y contraídos con otros operadores del mismo (mayoristas, restauradores, etc.)» (Paz Canalejo, 2012, p. 136). Es decir, las Cofradías de Pescadores, a pesar de que son Corporaciones de Derecho Público, y, por tanto, jurídicamente dependientes de las Administraciones Públicas, tienen libertad para trabajar en la defensa de los intereses del sector (Cervera Paz, 2010, p. 23).

Precisamente, la STC 89/1989, de 11 de mayo, deja claro que las Corporaciones de Derecho público no se integran en la Administración, ni pueden ser consideradas entes públicos descentralizados, sin perjuicio de que, junto a fines privados también cumplan fines públicos (F.J. 4. ${ }^{\circ}$ ). Por 
su parte, la STC 132/1989, de 18 de julio, hace hincapié en la idea de que el cumplimiento de tales fines públicos se lleva a cabo a través de la colaboración con las distintas Administraciones, incidiendo, nuevamente, en la idea de que ello no conlleva su integración en las mismas (F.J. 6. ${ }^{\circ}$ ). Y en el mismo sentido se pronuncia también la STC 139/1989, de 20 de julio (F.J. 2. ${ }^{\circ}$ ). Por consiguiente, debe concluirse que la consideración de las Cofradías de Pescadores como Corporación de Derecho público, de entrada, no impide la posibilidad de considerarlas como entidad de la Economía Social. Y es que, a falta de estas matizaciones, podría pensarse que el carácter de Corporación de Derecho público que presentan las Cofradías de Pescadores imposibilita por sí el cumplimiento de uno de los principios orientadores de la Economía Social que se recogen en el artículo 4 de la Ley 5/2011, de 29 de marzo, de Economía Social, a saber, el relativo a la «independencia respecto a los poderes públicos». No en vano, en sintonía con las matizaciones realizadas, la propia Ley 16/1998, de 25 de junio, de Cofradías de Pescadores, de la Comunidad Autónoma de Euskadi, establece que las Cofradías de Pescadores «están dotadas de autonomía para la gestión de sus intereses y recursos propios y su actuación estará sometida al tráfico privado, sin perjuicio de la regulación por el Derecho público de los actos que conciernen a su constitución, organización y procedimiento electoral, así como aquellos otros realizados en virtud de su carácter de corporación de Derecho público que tengan la consideración de administrativos (artículo 2.2) ${ }^{2}$. En esa línea, debe recordarse que es función de las Cofradías de Pescadores «la gestión y administración de sus bienes y derechos y de los que adquieran por cualquier título» (artículo 4.k). De ese modo, los Estatutos de las Cofradías de Pescadores también se refieren expresamente a su «autonomía funcional y económica» (vid. Estatutos de las Cofradías de Pescadores de Armintza, Bermeo, Donostia, Lekeitio, Getaria, Hondarribia, Pasajes, Zierbena y Santurtzi), o a la «completa autonomía dentro de su campo de acción» (vid. Estatutos de la Cofradía de Pescadores de Orio).

Salvado, por todo lo indicado, el posible incumplimiento de las Cofradías de Pescadores del principio relativo a la «independencia respecto a los poderes públicos», en principio, parece que podría reconocerse su carácter de entidad de la Economía Social, tal y como se establece en el artículo 5.1 de la Ley 5/2011, de 29 de marzo, de Economía Social. Decimos en principio, porque, a tenor de lo dispuesto en el artículo 2 de dicha norma, cabría la posibilidad de probar que no cabe tal calificación. Por ello, en el siguiente apartado, resulta pertinente averiguar si, en la práctica, las Cofra-

2 En ese mismo sentido se pronuncian expresamente los Estatutos de la Cofradía de Pescadores de Orio. 
días de Pescadores cumplen con el resto de principios orientativos recogidos en el artículo 4. Además, conforme a la conjunción de los artículos 2 y el 5, las Cofradías deben cumplir, al igual que el resto de entidades de la Economía Social, con otros dos requisitos, a saber, por una parte, desarrollar actividad económica y, por otra parte, satisfacer bien el interés colectivo de sus integrantes, bien el interés general económico y social, o ambos (ARrieta Idiakez, 2014, p. 40). En última instancia, será el resultado de haber comprobado que, en la práctica, las Cofradías de Pescadores cumplen con todos esos principios y requisitos, lo que justifique el apoyo público a las Cofradías de Pescadores, en tanto en cuanto se trata de verdaderas entidades de la Economía Social, más allá del nomen iuris. Es decir, solo así cabe medir, en sus justos términos, el impacto socioeconómico de las once Cofradías de Pescadores existentes en la Comunidad Autónoma de Euskadi ${ }^{3}$, más allá de los datos que corroboran que, a fecha de 31 de diciembre de 2019, estas daban empleo a 35 personas, contaban con 315 cofrades o personal asociado, con 62 embarcaciones, y obtuvieron un volumen de producción total comercializada de 17.247 toneladas, lo que supone, en primera venta, un montante equivalente a 26.352 .560 euros (Informe del Plan de Producción y Comercialización correspondiente a 2019 entregado al Gobierno Vasco).

Pero antes de adentrarnos en el análisis del cumplimiento, por parte de las Cofradías de Pescadores, de las exigencias ya mencionadas, resulta conveniente observar cómo incluso mucho antes de su configuración como entidades de la Economía social, la doctrina científica destacaba algunos de sus rasgos o elementos que resultan consustanciales a la Economía Social.

Así, Franquesa destaca, entre otras, las siguientes funciones (FranQUESA, 2005, pp. 5-6):

a) Incluyen a todos los pescadores que están trabajando en su área geográfica.

b) La institución tiene una estructura democrática con dos grupos representativos: los propietarios y los marineros. Cada grupo elige el mismo número de miembros para los cuerpos ejecutivos.

c) Es obligatorio para sus miembros vender en la subasta de la Cofradía.

d) No pueden acumular beneficios. Los excedentes se destinan a mejorar las infraestructuras (normalmente las Cofradías de Pescadores proveen de tiendas con equipamiento para barcos, artes, hielo, etc.) o los redistribuye entre sus miembros (por ejemplo, con pensiones adicionales a los miembros retirados o viudas, fiestas rituales, etc.).

3 Se trata de las Cofradías de Pescadores de Zierbena, Santurtzi, Armintza, Bermeo, Lekeitio, Ondarroa, Hondarribia, Pasaia, Donostia, Orio y Getaria. 
e) Bajo el marco legal establecido por la Comisión Europea, el Ministerio de Agricultura, Pesca y Alimentación y el Departamento de Agricultura, Pesca e Industria Alimentaria del Gobierno Vasco, pueden establecer reglas adicionales: controlar el tiempo de pesca, aceptar o prohibir ciertos artes de pesca en el área, establecer reservas o vedas, etc.

Por su parte, Cervera Paz, tras realizar un estudio empírico, concluye que las Cofradías de Pescadores, con independencia de ser Corporaciones de Derecho Público, por el resto de sus características pueden encuadrarse dentro del marco de la Economía Social. Concretamente, de su estudio pueden resaltarse los siguientes resultados (Cervera Paz, 2010, pp. 18-28):

a) Son asociaciones de carácter voluntario en cuanto a su afiliación, no existiendo discriminación por razones sociales, políticas, religiosas o de sexo.

b) Agrupan a individuos con los mismos objetivos y dedicados a actividades productivas similares, con el fin de practicar la autoayuda y obtener así los beneficios que únicamente se pueden conseguir gracias al movimiento asociacionista en el sector pesquero.

c) Presentan una base ética inspirada en los valores de honestidad, transparencia, responsabilidad y vocación social.

d) Emplean mecanismos de gestión democrática o mecanismos de decisión democráticos. Son los cofrades los que mediante sufragio determinan sus representantes, de forma y manera que el poder pasa de estar en manos del capital a manos del trabajo. Al estar asociados a ellas los armadores (capital o empresario, aunque también muchas veces sean trabajadores en sus propios barcos), patrones (que pueden ser a su vez armadores) y marineros (o trabajadores propiamente dichos), se reparte el poder entre los mismos con mecanismos de representación proporcionales, en los que siempre se requiere que estén presentes ambas partes y ninguna en menoscabo de la otra. Asimismo, cabe hablar de democracia económica, pues son los asociados quienes definen las líneas de actuación de la Cofradía de Pescadores.

e) Están obligadas por ley a suministrar información a sus asociados para que haya transparencia en su gestión.

f) Buscan el desarrollo sostenible de las comunidades en las que se ubican.

g) El patrimonio pertenece a la Cofradía de Pescadores y no a los cofrades. 


\section{Identificación y concreción práctica de los principios de la economía social en las cofradías de pescadores de Euskadi}

\subsection{Centralidad de las personas y del fin social}

La centralidad de las personas como característica de las Cofradías de Pescadores se vincula, de entrada, a su naturaleza de institución «sin ánimo de lucro», pues se considera que con ello se hace referencia a la "justicia en la distribución de la riqueza generada o equidad» (Moreno Ruiz, 2000, p. 59). Aunque dicha característica no se recoja en la Ley 16/1998, de 25 de junio, de Cofradías de Pescadores, de la Comunidad Autónoma de Euskadi, como se ha visto anteriormente (supra 1), forma parte de las definiciones dadas tanto por la Ley 3/2001, de 26 de marzo, de Pesca Marítima del Estado (cfr. artículo 45.1), como por CEPES. Por su parte, entre los Estatutos, tan solo se refieren a dicha característica los correspondientes a la Cofradía de Pescadores de Donostia (cfr. artículos 3, 4, 32 y 33). En ese sentido, se realizan, además, las siguientes matizaciones:

a) «Las cuotas de los Cofrades deberán abarcar exclusivamente la cuantía necesaria para el sostenimiento de los gastos de la Cofradía y de los gastos necesarios para el cumplimiento de los fines de la misma» (artículo 3).

b) «En el caso de que [en su ejercicio económico] se produzca algún sobrante o superávit, este pasará a engrosar los fondos del ejercicio siguiente, con el objeto de que las cuotas y aportaciones de los cofrades sean en todo momento lo más moderadas posibles, y todo ello en base a que esta Cofradía no persigue con sus ingresos ningún ánimo de lucro, sino solamente cubrir sus presupuestos de costos y gastos, e inversiones para financiar otros servicios complementarios, así como sus obras sociales» (artículo 32).

Precisamente, como puede apreciarse en esta segunda matización, como consecuencia de tratarse de una institución sin ánimo de lucro, los resultados obtenidos de la actividad económica de la Cofradía se aplican al fin social objeto de la misma, lo que coincide con el segundo de los cuatro principios orientadores establecidos por el artículo 4 de la Ley 5/2011, de 29 de marzo, de Economía Social. En la misma línea, en los casos de disolución de las cofradías, tal y como ha sucedido en Elantxobe, Mundaka y Mutriku, los estatutos prevén, generalmente, que el remanente del capital que pueda existir, una vez cumplidas las obligaciones pendientes, debe destinarse a fines sociales, de interés del municipio o benéficos. Ahora bien, en algunos casos, el destino del remanente se deja en manos de lo que acuerde el Pleno de la Asamblea General, y, en el particular caso de los Estatutos de 
la Cofradía de Santurtzi, se dice que tendrá prioridad su distribución entre los socios en proporción directa a su antigüedad como tales, lo que vuelve a dejar claro la centralidad de la persona sobre el capital.

Asimismo, la centralidad de las personas está presente en multitud de aspectos contemplados en los Estatutos de las Cofradías de Pescadores.

Esto sucede, ni más ni menos, con el objetivo fundamental de las Cofradías de Pescadores, en la medida en que consiste en el incremento y desarrollo de las actividades que dimanen del ejercicio de la pesca, el marisqueo y la acuicultura, a los efectos de aumentar su rendimiento, así como el bienestar moral y material de los trabajadores del mar. Ciertamente, el aumento del rendimiento de las mencionadas actividades reporta en el interés colectivo de sus integrantes; requisito, este último imprescindible, como se ha indicado (supra 1), para que jurídicamente pueda hablarse de la existencia de una entidad de la Economía Social a tenor de lo establecido en el artículo 2 de la Ley 5/2011, de 29 de marzo, de Economía Social.

Y entre los fines establecidos para conseguir dicho objetivo, también se recogen aspectos ligados a la centralidad de la persona, desde el punto de vista de la promoción de la solidaridad interna a la que hace alusión el tercero de los principios orientadores de la Economía Social recogidos en la mencionada Ley 5/2011, tales como:

a) La defensa de los intereses generales de los asociados en su actividad pesquera y comercializadora.

b) Promover y desarrollar actividades formativas, recreativas, culturales y sociales para sus miembros. Especial interés suscita la actividad formativa que se está llevando a cabo a través de la convocatoria de ciclos de grado medio de puente para la obtención del título de patrón de litoral. Se trata de que personas sin estudios puedan acceder a titulaciones de grado medio, y con ello les resulte más atractivo seguir trabajando en el mar. Para ello, estas personas, con solo acreditar su experiencia consiguen convalidar una serie de asignaturas que les permite obtener el certificado de profesionalidad, lo que supone obtener el equivalente a la ESO, como prueba de acceso para cursar estudios de grado medio, tales como maquinista o el ya aludido patrón de litoral. En esa línea, no cabe olvidar que el Dictamen del Comité Europeo de las Regiones - Nueva agenda europea para el desarrollo de las industrias marítimas, de 27 de junio de 2019—, llama la atención «sobre la necesidad de adecuar e impulsar la formación marítimo-pesquera de forma que sea un elemento de apoyo al relevo generacional en la pesca, la acuicultura y el marisqueo». En la misma línea, el Dictamen del Comité Econó- 
mico y Social Europeo sobre "Dimensión social de la pesca», de 25 de septiembre de 2019, «considera prioritario aumentar el atractivo de la profesión pesquera, atraer talento y facilitar la incorporación de los jóvenes a la actividad», con la finalidad de «dar respuesta a la escasez de tripulantes, una problemática que pone en riesgo la viabilidad del sector, y que se ha identificado hoy en día como el problema más grave al que se enfrenta la flota pesquera europea». Por todo ello, recomienda "potenciar la carrera marítimo-pesquera y dar a conocer la pesca como una salida profesional digna y llena de oportunidades para los jóvenes», e insta a la Comisión Europea «a promover una formación náutico-pesquera como método para profesionalizar el sector y mejorar su capacitación de cara a favorecer un empleo de calidad».

c) Tratar de incrementar y completar la acción asistencial, en la medida de lo posible, a favor de los pescadores y sus familias, acordando lo necesario para mejorar la situación del pescador anciano o inválido. En este sentido, en algunas Cofradías, si al final del ejercicio económico existen beneficios, existe la costumbre de destinar una parte de dichos beneficios a los cofrades jubilados. Y otro tanto ha sucedido, históricamente, con el abono de las cuotas a seguros sanitarios privados (v.gr. IMQ). Estatutariamente, es digna de mención la previsión que contienen los Estatutos de la Cofradía de Donostia, según la cual la Cofradía puede acordar la prestación de avales o fianzas a favor de sus asociados ante entidades de crédito oficial siempre que tales avales o fianzas se refieran a operaciones relacionadas con las actividades pesqueras de los socios interesados (cfr. artículo 36).

d) Dirimir las cuestiones planteadas entre los cofrades dentro del campo de actividades profesionales, siempre que se trate de intereses comunes de todos ellos.

e) Facilitar la libre y justa convivencia entre empresarios y trabajadores en orden a la potenciación de sus intereses comunes.

f) La gestión de los recursos pesqueros que individual o colectivamente puedan poner a su disposición los asociados.

g) La gestión y administración de sus bienes y derechos y de los que se adquieran por cualquier título.

Igualmente, deben vincularse a la solidaridad interna aludida diversas prácticas basadas en los usos y costumbres o establecidas en reglamentos de régimen interno. Entre dichos usos y costumbres actualmente debe resaltarse por su importancia el aplicado respecto al sistema de cupos máximos de pesca de verdel y anchoa, que opera de la siguiente manera: cuando 
una embarcación ha capturado el cupo máximo que le corresponde, otorga el excedente a aquellas embarcaciones que todavía no han alcanzado su cupo máximo. Además, esta medida posibilita un uso racional de la pesca, sin que los excesos de capturas supongan un desperdicio. Por su parte, entre los reglamentos de régimen interno destaca el relativo al remolque existente en la Federación Guipuzcoana de Cofradías de Pescadores, y que es un buen ejemplo del auxilio mutuo practicado entre diversas embarcaciones, sobre todo, en situaciones de averías en alta mar.

En cualquier caso, no cabe entender dicha solidaridad interna sin hacer referencia a otra de las características esenciales que presentan las Cofradías de Pescadores, como resulta ser el carácter voluntario o principio de puerta abierta para ser miembro asociado. Se trata de una característica o principio contemplado en el artículo 7 de la Ley 16/1998, de 25 de junio, de Cofradías de Pescadores, de la Comunidad Autónoma de Euskadi, y que se recoge, igualmente, en los Estatutos de las diversas Cofradías de Pescadores. Se trata de que los armadores y tripulantes de las embarcaciones con base en el puerto al que pertenece la correspondiente Cofradía, que profesionalmente se dediquen a la pesca, puedan adquirir libremente la condición de miembro de la Cofradía por el mero hecho de ejercer dicha actividad y solicitar su inclusión. En consecuencia, la Junta Directiva solamente podrá denegar el acceso si el solicitante incumple o hubiera incumplido previamente los estatutos de la Cofradía.

Una vez aceptados como miembros de la Cofradía, todos los cofrades o asociados gozan de igualdad de derechos y obligaciones. Pero sin duda, dicha igualdad se manifiesta, principalmente, en la gestión democrática y participativa, que lleva a priorizar la toma de decisiones en función de las personas, tal y como se expresa en el primer principio orientador de la Economía Social, recogido en el artículo 4 de la Ley 5/2011, de 29 de marzo, de Economía Social.

En efecto, el fundamento de la democracia participativa queda patente en la Ley 16/1998, de 25 de junio, de Cofradías de Pescadores, de la Comunidad Autónoma de Euskadi, al afirmarse que «las cofradías de pescadores estarán constituidas por los armadores y por el personal laboral dependiente de los mismos que ejerzan la actividad pesquera, como actividad profesional, embarcados en los buques de pesca con puerto base en el ámbito territorial de la cofradía» (artículo 6.1). En dicha afirmación late la defensa de los intereses de las dos partes afectadas por la actividad pesquera, como actividad profesional, siguiendo así el esquema organizativo de los antiguos gremios.

$\mathrm{Y}$ de acuerdo con dicho fundamento, la democracia participativa se manifiesta en la composición de los órganos rectores de las Cofradías de Pescadores. 
Así, conforme a la mencionada Ley 16/1998, la Asamblea General actúa como «órgano superior de representación de todos los miembros y de control de los demás órganos rectores» (artículo 17.1). No en vano, "estará constituida por los representantes de los armadores y del personal laboral dependiente de los mismos, según el criterio de representación paritaria entre ambos sectores» (artículo 17.2). Ello no obstante, «los estatutos podrán establecer que la Asamblea General de la cofradía esté formada por todos los miembros de la misma, sin perjuicio de la representación paritaria en la emisión del voto" (artículo 17.2, in fine), tal y como se prevé, por ejemplo, en los Estatutos de las Cofradías de Pescadores de Donostia (cfr. artículo 14), Getaria (cfr. artículo 12) y Pasajes (cfr. artículo 12). Aun así, tampoco cabe desconocer que los Estatutos de las Cofradías reconocen la posibilidad de que la Asamblea General podrá estar formada por todos los miembros de la Cofradía, sin perjuicio de la representación paritaria en la emisión del voto, en casos particulares como la rendición de cuentas, la aprobación de presupuestos, y cualquier otro caso en que así lo exijan los Estatutos, las disposiciones legales vigentes o cuando así se acuerde por parte de los integrantes de la Asamblea General (vgr. Estatutos de las Cofradías de Armintza, Bermeo, Ondarroa, Lekeitio, Zierbena y Santurtzi). Cuestión distinta es que puedan asistir a la Asamblea General, con voz pero sin voto, todos los demás cofrades, tal y como se establece en los Estatutos de las Cofradías de Pescadores de Hondarribia (cfr. artículo 14) y Orio (cfr. artículo 14).

Por su parte, la Junta Directiva y el Presidente son elegidos entre los miembros de la Asamblea General (artículo 18.b). Además, «la Junta Directiva estará constituida por el Presidente, el Vicepresidente y un número de miembros de la Asamblea General elegidos por esta, siguiendo los mismos criterios de representación paritaria previstos en la misma» (artículo 19.2), si bien no cabe desconocer que existe una excepción en el caso de los Estatutos de la Cofradía de Armintza, dado que, contraviniendo el mandato legal, se altera dicho criterio, abogándose por que la Junta Directiva esté formada por cinco miembros, incluidos el Presidente y el Vicepresidente, de los cuales cuatro serán armadores y uno tripulante, aunque todos ellos elegidos por y de entre los representantes de los armadores y tripulantes que componen la Asamblea General.

Del mismo modo, la gestión de las Cofradías de Pescadores es transparente. Por un parte, porque la Asamblea General, como órgano superior de representación de todos los cofrades, y, como se ha visto, dotado de estructura paritaria, tiene competencias que permiten llevar a cabo una actuación transparente en importantes materias, tales como la aprobación de presupuestos de ingresos y gastos, la aprobación de cuotas o derramas, la aprobación del balance y de los estados financieros o cuentas de explo- 
tación del ejercicio presupuestario o la aprobación de la memoria, los proyectos y programas de actuación de la Cofradía. Y, por otra parte, debido a que, por Estatutos, todos los miembros de las mismas tienen derecho a ser informados, oportunamente, de las actuaciones y funcionamiento de la Cofradía y de las cuestiones que les afectan. Y, recíprocamente, también se regula estatutariamente el deber de los cofrades de facilitar información solvente y responsable sobre las cuestiones que no tengan naturaleza reservada, cuando lo sea requerido por la Cofradía.

Asimismo, como buena práctica de transparencia de la gestión, puede citarse lo previsto en los Estatutos de la Cofradía de Pescadores de Orio respecto a la obligación de someterse a una auditoría externa de cuentas (cfr. artículo 46).

\subsection{Dimensión económica y empresarial}

No hay duda de que las Cofradías de Pescadores, pese a tratarse de entidades sin ánimo de lucro, desempeñan actividades económicas, tales como la venta de productos del mar, la fabricación de hielo y la creación y gobierno efectivo de sociedades instrumentales. Así, los Estatutos de las Cofradías, al regular sus fines, se refieren, más concretamente a «crear y promocionar los servicios de interés común que se consideren convenientes, tales como ventas de pertrechos de pesca, economatos, plantes de congelación, fábricas de hielo, varaderos, participación en buques de pesca», a «establecer los sistemas organizativos y de comercialización de sus productos pesqueros» y a "impulsar la adopción de medidas tendentes a tecnificar el proceso extractivo y de conservación y a la presentación, normalización y comercialización de productos pesqueros y de calidad». En concreto, respecto a la venta de los productos del mar debe hacerse hincapié en la idea de que es obligatorio para los miembros de la Cofradía vender todas sus capturas en la subasta de la Cofradía.

En cambio, las Cofradías de Pescadores, directamente no ejercen una actividad empresarial porque no son empresas, sino Corporaciones de Derecho Público (Arrieta Idiakez, 2014, p. 39). Sin embargo, indirectamente, a través de la asociación con otras entidades o empresas, en la práctica, sí la ejercen. Así, en los Estatutos de las Cofradías de Pescadores se menciona expresamente, entre los fines de las mismas el «impulsar procesos asociativos y formalizar convenios de colaboración comercial o formalizar acuerdos interprofesionales con otras organizaciones y empresas con el fin de conseguir eficacia y rentabilidad en la actividad pesquera y una mayor participación en los procesos de transformación y comercialización de los productos pesqueros». Es más, la propia Exposición de Motivos de la 
Ley 16/1998, de 25 de junio, de Cofradías de Pescadores, de la Comunidad Autónoma de Euskadi, también se refiere a esta finalidad, contextualizándola respecto a las adaptaciones que la realidad socioeconómica impone y a las circunstancias que aconsejan el establecimiento de nuevos cometidos.

En ese sentido, constituye un buen ejemplo la empresa Matxitxako Moluscos SL, creada en 2015, en Ondarroa, y participada, entre otros, por las Cofradías de Pescadores de Ondarroa y Lekeitio, la Federación de Cofradías de Pescadores de Gipuzkoa, la Fundación Azti y las empresas Arrankoba SL e Itsaskorda SL., con la finalidad de crear el primer polígono marino de producción acuícola (mejillones y ostras) en el Mar Cantábrico. Al fin y a la postre, ello no constituye más que un ejemplo de cómo las Cofradías de Pescadores pueden actuar como nicho de nuevas formas de empleo (v.gr. acuicultura, manipulado de pescado, turismo). Es más, en el particular caso de la acuicultura, debe considerarse, en la línea de lo señalado por el Dictamen del Comité Económico y Social Europeo sobre «La bioeconomía azul», de 30 de octubre de 2019, que:

Encierra un potencial significativo para continuar creciendo (...) [y que] debería poder producir bastante más biomasa de forma sostenible incrementando el número de especies utilizadas, incluidas aquellas de niveles tróficos inferiores (como algas y moluscos).

No en vano, dicho Dictamen incluye a la acuicultura dentro de la denominada «bioeconomía azul», que es definida como:

Las actividades económicas y la creación de valor basadas en el uso sostenible e inteligente de recursos acuáticos renovables y los conocimientos técnicos en este campo.

Respecto a la misma, ya el Dictamen del Comité Europeo de las Regiones - Nueva agenda europea para el desarrollo de las industrias marítimas, de 27 de junio de 2019- lo había considerado como «sector emergente», al destacar:

Su potencial prometedor, pero aún poco cualificado (...), con múltiples aplicaciones de mercado (alimentos y piensos, farmacología, cosmética, energia) y un fuerte impacto territorial (...).

Además, este Dictamen, como acompañamiento del desarrollo de la bioeconomía azul, destaca la importancia de la economía circular marítima, consistente, entre otros aspectos, en la aplicación del principio de 
descartes nulos en la pesca, la recuperación de la línea de bajamar, los residuos de la valorización de las algas o el tratamiento de residuos y plásticos.

También merecen especial atención las nuevas posibilidades que se abren con el Real Decreto 239/2019, de 5 de abril, por el que se establecen las condiciones para el desarrollo de la actividad de pesca-turismo, así como con el Decreto 143/2021, de 25 de mayo, de pesca-turismo, demostraciones de pesca y turismo pesquero o marinero en aguas marítimas y continentales de la Comunidad Autónoma de Euskadi, tal y como se comentará en el apartado 2.3 de este estudio. En esa línea, debe subrayarse que el Dictamen del Comité Europeo de las Regiones - Nueva agenda europea para el desarrollo de las industrias marítimas, de 27 de junio de 2019- recuerda:

La importancia socioeconómica de la pesca y de las actividades maritimas para suministrar alimentos de calidad y seguridad probada; (...) la importancia de su dimensión cultural y patrimonial, elemento fundamental de dinamización turistica (...).

E insiste:

En las necesarias sinergias y complementariedades entre estas actividades tradicionales y las nuevas industrias que se desarrollen, con el fin de generar empleo y desarrollo sostenible.

En parecidos términos, el Dictamen del Comité Económico y Social Europeo sobre "Dimensión social de la pesca», de 25 de septiembre de 2019, considera fundamental:

Diseñar las politicas pesqueras no solo desde la perspectiva medioambiental, sino teniendo en cuenta la importancia global de la pesca, su impacto en el resto de la economía y su papel en la seguridad marítima, en el suministro de alimentos sanos y saludables y en la fijación de población en zonas vulnerables.

Se subraya, además:

La importancia de la pesca a pequeña escala y la necesidad de garantizar un entorno empresarial favorable, que permita a este sector funcionar de forma sostenible y ofrecer puestos de trabajo especialmente importantes en muchas comunidades costeras.

Ahora bien, se considera que toda colaboración comercial con otras organizaciones y empresas debe partir del respeto a la autonomía de las Co- 
fradías de Pescadores, con el objetivo de salvaguardar los principios de la Economía Social. De lo contrario, estas podrían perder su naturaleza de entidad de la Economía Social y con ello muchos de los beneficios que obtienen en calidad de tales.

Asimismo, debe resaltarse la intercooperación existente entre las distintas Cofradías de Pescadores, así como la integración de las Cofradías de Bizkaia en la Federación de Cofradías de Pescadores de Bizkaia, y la integración de las Cofradías de Gipuzkoa en la Federación de Cofradías de Pescadores de Gipuzkoa, para el mejor cumplimiento de sus fines.

Y, por último, no cabe olvidar que las Cofradías de Pescadores promueven acuerdos con las instituciones financieras con el fin de obtener la mejor utilización de los instrumentos financieros en el desarrollo de la actividad pesquera, y formalizan acuerdos con las Administraciones públicas con el fin de realizar campańas de identificación de mercados y de propaganda y promoción de los productos pesqueros de la Comunidad Autónoma de Euskadi.

\subsection{Compromiso con la comunidad en la que se entroncan}

Las Cofradías de Pescadores demuestran un compromiso con el desarrollo local en la medida en que además de generar puestos de trabajo, fomentan la actividad económica y constituyen una fuente de ingresos que revierte en sus correspondientes municipios.

Además, la colaboración y asociación con otras entidades y empresas también demuestra un compromiso no solo con el desarrollo local sino que también con la cohesión social. Ante la actual decadencia del sector pesquero, cobran gran importancia las iniciativas tendentes a diversificar la actividad pesquera o a completarla. En esta línea, debe destacarse, sobremanera, la Estrategia de Desarrollo Local que se lleva a cabo por el Grupo de Acción Local Pesquero y Acuícola «Itsas Garapen Elkartea, FLAG» (http://www.itsasgarapen.eus/es/), constituido el 16 de febrero de 2016, en la que también participan las Federaciones de Cofradías de Pescadores de Bizkaia y Gipuzkoa, y que se constituye en el cauce de las ayudas económicas para el desarrollo sostenible de las zonas pesqueras provenientes del Fondo Europeo Marítimo y Pesquero (FEMP), regulado por el Reglamento (UE) 508/2014, del Parlamento Europeo y del Consejo, de 15 de mayo, con destino a la la Comunidad Autónoma de Euskadi. Hay que tener en cuenta, que, conforme al propio Reglamento (UE) 508/2014 y al Reglamento de Ejecución (UE) 771/2014, de la Comisión, de 14 de julio, entre otras prioridades, el FEMP contribuye a «fomentar una pesca sostenible desde el punto de vista medioambiental, eficiente en el uso de los re- 
cursos, innovadora, competitiva y basada en el conocimiento" (respectivamente, artículo 6.2 y Anexo, apartado 8.2). Además, dicha prioridad se vincula a uno de los objetivos a los que debe contribuir el FEMP, a tenor de lo dispuesto en el artículo 5.a del Reglamento (UE) 508/2014.

Ya a nivel local, debe mencionarse la Asociación «Bermeo Capital Mundial del Atún", fundada el 27 de marzo de 2018, y de la que forman parte, junto a la Cofradía de Pescadores, la Fundación AZTI, el Ayuntamiento de Bermeo, la Diputación Foral de Bizkaia, el Gobierno Vasco, la Asociación Nacional de Armadores de Buques Atuneros Congeladores (ANABAC), la Asociación de Grandes Atuneros Congeladores (AGAC) y las empresas Zallo SA, Serrats SA, Salica SA y Gaviota SL.

En lo que respecta a la sostenibilidad medioambiental, deben resaltarse, por una parte, el Código de Conducta y Buenas Prácticas, y Objetivos, de las Pesquería de la Flota al Cerco Cantábrica, suscrito por las Federaciones de Cofradías de Pescadores de Bizkaia y Gipuzkoa, y, por otra parte, el Certificado MSC (Marine Stewardship Council) obtenido por ambas federaciones para las pesquerías de anchoa y bonito del norte ${ }^{5}$. No en vano, hay que recordar que el Reglamento (UE) 1380/2013, del Parlamento Europeo y del Consejo, de 11 de diciembre, sobre la política pesquera común, fija como uno de sus objetivos que «las actividades de la pesca y la acuicultura sean sostenibles ambientalmente a largo plazo y se gestionen de forma coherente con los objetivos de generar beneficios económicos, sociales y de empleo, y de contribuir a la disponibilidad de productos alimenticios» (artículo 2.1). Igualmente, la Resolución del Comité de las Regiones - el Pacto Verde en colaboración con los entes locales y regionales, de 5 de diciembre de 2019- destaca la importancia de una pesca sostenible para el equilibrio de las zonas costeras. Así, como venimos analizando, las Cofradías de Pescadores, se convierten en importantes agentes para conseguir dicho objetivo.

De este modo, conforme se indica en la Exposición de Motivos del ya mencionado Real Decreto 239/2019, de 5 de abril, por el que se establecen las condiciones para el desarrollo de la actividad de pesca-turismo:

Una de las formas de contribuir a (...) [la] sostenibilidad [medioambiental] es la introducción de medidas de diversificación. La diversificación

5 Marine Stewardship Council (MSC) es una organización internacional sin ánimo de lucro creada para ayudar a transformar el mercado de productos del mar hacia la sostenibilidad. MSC opera el único programa de ecoetiquetado para pesquerías de captura salvaje consistente con el Código de Buenas Prácticas de ISEAL para la Fijación de Estándares Sociales y Medioambientales. Estas directrices se basan en el Código de Conducta de FAO para la Pesca Responsable (www.msc.org/es). 
pesquera y acuicola en sus diferentes vertientes supone nuevas fuentes de ingreso para el sector pesquero. En este ámbito, el turismo pesquero o marinero adquiere un gran potencial y nuevas oportunidades laborales que surgen en relación con el mar, pero que convergen también con otros sectores, particularmente la pesca-turismo.

En concreto, el Real Decreto 239/2019 regula como actividad complementaria al sector pesquero las condiciones básicas para el desarrollo de la actividad de pesca-turismo respecto de la actividad extractiva y a acuicultura ejercida a bordo de buques pesqueros (cfr. artículo 1). Al fin y a la postre, la pesca-turismo se considera una actividad asociada del turismo pesquero o marinero (cfr. Exposición de Motivos). Así, de acuerdo con las definiciones que contiene la Ley 3/2001, de 26 de marzo, de Pesca Marítima del Estado, se entiende por «turismo pesquero o marítimo» la:

Actividad desarrollada por los colectivos de profesionales del mar, mediante contraprestación económica, orientada a la valorización y difusión de las actividades y productos del medio marino, asi como de las costumbres, tradiciones, patrimonio y cultura marinera, que por ello trasciende de la mera actividad extractiva y comercial.

Por su parte, la «pesca-turismo» se define como el:

Tipo de actividad turismo pesquero o marinero desarrollada a bordo de embarcaciones pesqueras por parte de profesionales del sector, mediante contraprestación económica, que tiene por objeto la valorización y difusión de su trabajo en el medio marino, en la que los turistas embarcados no podrán ejercer la actividad pesquera.

En suma, el Real Decreto 239/2019 aboga por la diversificación pesquera o acuícola, conforme a la definición que, sobre la misma, también establece la Ley 3/2001, de 26 de marzo, de Pesca Marítima del Estado:

El desarrollo de actividades complementarias realizadas por profesionales del sector pesquero, con el fin de reforzar la economía de las comunidades pesqueras.

Por su parte, el Decreto 143/2021, de 25 de mayo, de pesca-turismo, demostraciones de pesca y turismo pesquero o marinero en aguas marítimas y continentales de la Comunidad Autónoma de Euskadi, incide también en la importancia de la diversificación de las actividades realizadas en el marco de la pesca y respecto de otros sectores de la economía marítima. Con ello se pretende cumplir con una de las prioridades del Plan Estraté- 
gico de Pesca y Acuicultura Euskadi 2020, a saber, aumentar el empleo y la cohesión territorial. En concreto, se considera que (Exposición de Motivos):

El turismo marinero puede ayudar a diversificar la economía en las zonas pesqueras, mediante actividades complementarias que generen nuevos ingresos, promocionen los productos de la pesca y promuevan la recuperación de la cultura, tradiciones y patrimonio vinculados a estas profesiones, asi como generar puestos de trabajo.

Así, al concretar el objeto de regulación, el Decreto 143/2021 resulta más exhaustivo que el Real Decreto 239/2019, pues además de referirse al «turismo pesquero o marítimo» y a la "pesca-turismo", también se refiere expresamente a las "demostraciones de pesca». Se consideran todas ellas actividades complementarias del sector pesquero, pues, estando todas ellas vinculadas total o parcialmente con la pesca marítima y la acuicultura, coadyuvan a mejorar o complementar las rentas de las personas que integran dicho sector (cfr. artículo 1).

En ese sentido, respecto al Real Decreto 239/2019, se aprecian algunas matizaciones en la definición de las actividades consistentes en el «turismo pesquero o marítimo" y en la "pesca-turismo» (cfr. artículo 3).

Respecto al «turismo pesquero o marítimo», efectivamente, se matiza que, en todo caso, debe tratarse de una actividad que se desarrolle fuera de embarcaciones pesqueras, en puertos pesqueros, instalaciones de acuicultura y zonas limítrofes o continentales relacionadas con la pesca, acuicultura y el marisqueo.

En lo que se refiere a la "pesca-turismo», se concreta su contenido, y se diferencia del "turismo pesquero o marítimo", en la medida en que se señala expresamente que consiste en la pesca extractiva o de demostración a bordo de embarcaciones pesqueras por personas profesionales del sector. A pesar de que en la definición no se mencione que los turistas embarcados no podrán ejercer la actividad pesquera, el artículo 7.2 del Decreto lo señala expresamente. Igualmente, se especifica con mayor grado de detalle el objetivo de dicho turismo, al señalar que se trata de valorizar y difundir no solo las actividades desarrolladas por los profesionales del sector, como parece deducirse del Real Decreto 239/2019, sino que también las costumbres, tradiciones, patrimonio y cultura marinera.

Por último, la gran novedad que presenta el Decreto 143/2021 consiste en incluir como actividad complementaria del sector pesquero, dentro del objetivo principal de diversificar las actividades realizadas en el marco de la pesca y respecto de otros sectores de la economía marítima, la «demostración de pesca». Concretamente, se define a la misma como: 
Actividad realizada con cualquier arte de pesca, mediante contraprestación económica, que tiene como objetivo mostrar su funcionamiento y caracteristicas en el lugar de la extracción de recursos marinos, sin perjuicio de que de la demostración se pueda derivar la extracción accidental de una pequeña cantidad de recursos marinos.

Por último, las finalidades a las que deben responder todas esas actividades objeto del Decreto demuestran el compromiso con la comunidad de los puertos pesqueros y, por ende, con las localidades en las que se ubican los mismos, que se pretende adquirir mediante este tipo de normas, que, si bien no se dirigen exclusivamente a las cofradías de pescadores, no es menos cierto que las mismas están llamadas a jugar un papel fundamental.

De hecho, se faculta a las mismas para que, por una parte, puedan desarrollar las actividades de "pesca-turismo" y las "demostraciones de pesca", a través de las entidades mercantiles que puedan constituir junto con las personas titulares de las autorizaciones, concesiones y licencias de pesca, acuicultura marina o marisqueo desde embarcación, $y$, por otra parte, puedan, también a través de dichas entidades mercantiles, desarrollar actividades de "turismo pesquero o marinero", aunque para ello necesariamente deban constituir una entidad mercantil con operadores turísticos u otras empresas de servicios vinculados con el desarrollo de actividades turísticas, de recreo, educativas o culturales objeto del Decreto, siempre que dicha entidad mercantil se integre en su mayoría por empresas o entidades del sector de la pesca, el marisqueo o la acuicultura y que el porcentaje de acciones o participaciones pertenezca en más del $50 \%$ a las empresas o entidades del sector pesquero (cfr. artículo 4).

En concreto, las finalidades del Decreto son:

a) Difundir el patrimonio, las tradiciones, los oficios, la gastronomía y la cultura vinculados a la pesca, la acuicultura y el entorno de estos sectores.

b) Promover y revalorizar los productos de la pesca y la acuicultura.

c) Divulgar las técnicas pesqueras, los artes y utensilios de pesca y la evolución social, económica y tecnológica de este sector, y especialmente la encaminada a una mayor protección de los recursos y ecosistemas marinos.

d) Facilitar la adquisición de productos pesqueros y materiales de recuerdo vinculados a la actividad pesquera y la acuicultura, así como material divulgativo.

e) Promover la dinamización económica y la promoción de los sectores de la pesca y la acuicultura.

f) Visibilizar el trabajo de empacadoras, rederas y neskatilas. 


\section{Conclusiones}

La principal conclusión del análisis realizado es que las Cofradías de Pecadores de Euskadi sí cumplen con los principios de la Economía Social. La misma se sostiene por las siguientes conclusiones derivadas de dicha afirmación y que sirven para concretarla:

- Primera. La consideración de las Cofradías de Pescadores como Corporación de Derecho público no impide la posibilidad de considerarlas como entidad de la Economía Social, porque no deja de cumplirse el principio orientador de «independencia respecto a los poderes públicos» típico de las entidades de la Economía Social, en la medida en que las Cofradías de Pescadores están dotadas de autonomía para la gestión de sus intereses y recursos propios y su actuación se refiere al tráfico privado. En ese sentido, sus estatutos se refieren expresamente a su "autonomía funcional y económica».

- Segunda. La Ley 5/2011, de 29 de marzo, de Economía Social, se refiere expresamente a las Cofradías de Pescadores como entidades de la Economía Social. No obstante, y salvado el posible incumplimiento del principio relativo a la «independencia respecto a los poderes públicos», resulta pertinente averiguar si, en la práctica, las Cofradías de Pescadores cumplen con el resto de principios orientativos de la Economía Social. Además, las Cofradías deben cumplir, al igual que el resto de entidades de la Economía Social, con otros dos requisitos, a saber, por una parte, desarrollar actividad económica y, por otra parte, satisfacer bien el interés colectivo de sus integrantes, bien el interés general económico y social, o ambos.

- Tercera. Como consecuencia de tratarse de una institución sin ánimo de lucro, los resultados obtenidos de la actividad económica de las Cofradías de Pescadores se aplican al fin social objeto de la misma.

- Cuarta. El objetivo fundamental de las Cofradías de Pescadores consiste en el incremento y desarrollo de las actividades que dimanen del ejercicio de la pesca, el marisqueo y la acuicultura, a los efectos de aumentar su rendimiento, así como el bienestar moral y material de los trabajadores del mar. Por consiguiente, el aumento del rendimiento de las mencionadas actividades reporta en el interés colectivo de sus integrantes.

- Quinta. Las Cofradías de Pescadores promueven la solidaridad interna a través de la defensa de los intereses generales de los asociados en su actividad pesquera y comercializadora, las actividades forma- 
tivas, la acción asistencial a favor de los pescadores y sus familias y diversas prácticas basadas en los usos y costumbres o establecidas en reglamentos de régimen interno.

- Sexta. El ingreso en las Cofradías de Pescadores es de carácter voluntario y obedece al principio de puerta abierta. Se trata de que los armadores y tripulantes de las embarcaciones con base en el puerto al que pertenece la correspondiente Cofradía, que profesionalmente se dediquen a la pesca, puedan adquirir libremente la condición de miembro de la Cofradía por el mero hecho de ejercer dicha actividad y solicitar su inclusión.

- Séptima. Todos los cofrades o asociados gozan de igualdad de derechos y obligaciones. Dicha igualdad se manifiesta, sobre todo, en la gestión democrática y participativa que se lleva a cabo en la composición de los órganos rectores de las Cofradías de Pescadores.

- Octava. La gestión de las Cofradías de Pescadores es transparente, manifestándose en la aprobación de presupuestos de ingresos y gastos, la aprobación de cuotas o derramas, la aprobación del balance y de los estados financieros o cuentas de explotación del ejercicio presupuestario o la aprobación de la memoria, los proyectos y programas de actuación de la Cofradía. Igualmente, todos los miembros de las mismas tienen derecho a ser informados, oportunamente, de las actuaciones y funcionamiento de la Cofradía y de las cuestiones que les afectan.

- Novena. Las Cofradías de Pescadores, pese a tratarse de entidades sin ánimo de lucro, desempeñan actividades económicas, tales como la venta de productos del mar, la fabricación de hielo y la creación y gobierno efectivo de sociedades instrumentales. Y aunque directamente no ejerzan una actividad empresarial porque no son empresas, sino Corporaciones de Derecho Público, indirectamente, a través de la asociación con otras entidades o empresas, en la práctica, sí la ejercen.

- Décima. Las Cofradías de Pescadores pueden actuar como nicho de nuevas formas de empleo (v.gr. acuicultura, manipulado de pescado, turismo).

- Undécima. Existe una intercooperación entre las distintas Cofradías de Pescadores, así como la integración de las Cofradías de Bizkaia en la Federación de Cofradías de Pescadores de Bizkaia, y la integración de las Cofradías de Gipuzkoa en la Federación de Cofradías de Pescadores de Gipuzkoa, para el mejor cumplimiento de sus fines. Igualmente, las Cofradías de Pescadores promueven acuerdos con las instituciones financieras y formalizan acuerdos con las Administraciones públicas. 
- Duodécima. Las Cofradías de Pescadores están comprometidas con el desarrollo local en la medida en que además de generar puestos de trabajo, fomentan la actividad económica y constituyen una fuente de ingresos que revierte en sus correspondientes municipios. Y fruto de la colaboración y asociación con otras entidades y empresas están también comprometidas con la cohesión social. A tales efectos, y ante la situación decadente que presenta el sector pesquero, cobran especial importancia las iniciativas tendentes a diversificar la actividad pesquera o a completarla, más si cabe tras la entrada en vigor del Real Decreto 239/2019, de 5 de abril, por el que se establecen las condiciones para el desarrollo de la actividad de pesca-turismo, y del Decreto 143/2021, de 25 de mayo, de pesca-turismo, demostraciones de pesca y turismo pesquero o marinero en aguas marítimas y continentales de la Comunidad Autónoma de Euskadi. Del mismo modo, existe un compromiso para con la sostenibilidad medioambiental como queda patente con el Código de Conducta y Buenas Prácticas, y Objetivos, de las Pesquería de la Flota al Cerco Cantábrica y el Certificado MSC (Marine Stewardship Council) obtenido para las pesquerías de anchoa y bonito del norte.

\section{Bibliografía}

Arrieta Idiakez, Francisco Javier (2007). La Seguridad Social de los trabajadores del mar en el Derecho español. Vitoria-Gasteiz: Servicio Central de Publicaciones del Gobierno Vasco.

- (2014). «Concreción de las entidades de la Economía Social». En REVESCO, núm. 116.

Cervera Paz, Ángel (2010). «Percepción cooperativa de las Cofradías de Pescadores: un estudio empírico». En REVESCO, núm. 103.

Dictamen del Comité Económico y Social Europeo sobre «Dimensión social de la pesca», de 25 de septiembre de 2019.

Dictamen del Comité Económico y Social Europeo sobre «La bioeconomía azul», de 30 de octubre de 2019.

Dictamen del Comité Europeo de las Regiones - Nueva agenda europea para el desarrollo de las industrias marítimas, de 27 de junio de 2019-.

Erкoreka Gervasio, Josu Iñaki (1991). Análisis Histórico-Institucional de las Cofradias de Mareantes del País Vasco. Vitoria-Gasteiz: Servicio Central de Publicaciones del Gobierno Vasco.

FranQuesa, Ramón (2005). «Las Cofradías en España. Papel económico y cambios estructurales». En Quaderns Blaus, Universitat de Girona. Cátedra d' Estudis Marítims, 015. 
Lledó Martín, José (1943). La Pesca Nacional. Madrid: Ediciones Pegaso.

Moreno Ruiz, Rafael (2000). Mutualidades, Cooperativas, Seguro y Previsión Social. Madrid: CES.

Rebollo Puig, Manuel, Falcón y Tella, Ramón. y López Benítez, Mariano (1996). Naturaleza y régimen jurídico de las Cofradias de Pescadores. Córdoba: Servicio de Publicaciones Universidad de Córdoba.

Resolución del Comité de las Regiones —el Pacto Verde en colaboración con los entes locales y regionales, de 5 de diciembre de 2019-.

Rumeu de Armas, Antonio (1944). Historia de la Previsión Social en España. Madrid: Editorial Revista de Derecho Privado.

Paniagua Zurera, Manuel (2011). Las empresas de la economía social. Más allá del comentario a la Ley 5/2011, de Economía Social. Barcelona: Marcial Pons.

Paz Canalejo, Narciso (2012). Comentario sistemático a la Ley 5/2011, de Economía Social. Valencia: Tirant lo Blanch. 